\title{
Disturbances of the combustion processes in muscular disorders
}

\author{
IRENA NIEBRÓJ-DOBOSZ
}

From the Department of Neurology, School of Medicine, Warsaw, Poland

Attempts to elucidate carbohydrate metabolism in muscular diseases have been made by a relatively large number of authors but the results obtained, often contradictory, seem to be difficult to classify in a cycle of metabolic disorders. Nevertheless disturbances of carbohydrate metabolism appear to play an important role in the pathogenesis of muscular diseases. In view of the key position of pyruvic acid in the metabolic processes, it seemed interesting to investigate further its metabolism, all the more so, as the literature suggests that the blood pyruvic acid level is raised in progressive muscular dystrophy.

\section{METHODS AND MATERIAL}

With the subjects fasting, blood was sampled without venous stasis. The proteins were precipitated with trichloroacetic acid, and the following determinations were made on the filtrates. Pyruvic acid was determined by the method of Friedemann and Haugen (1943). Lactic acid determinations were carried out by the method described by Greig (1947). Citric acid was determined after

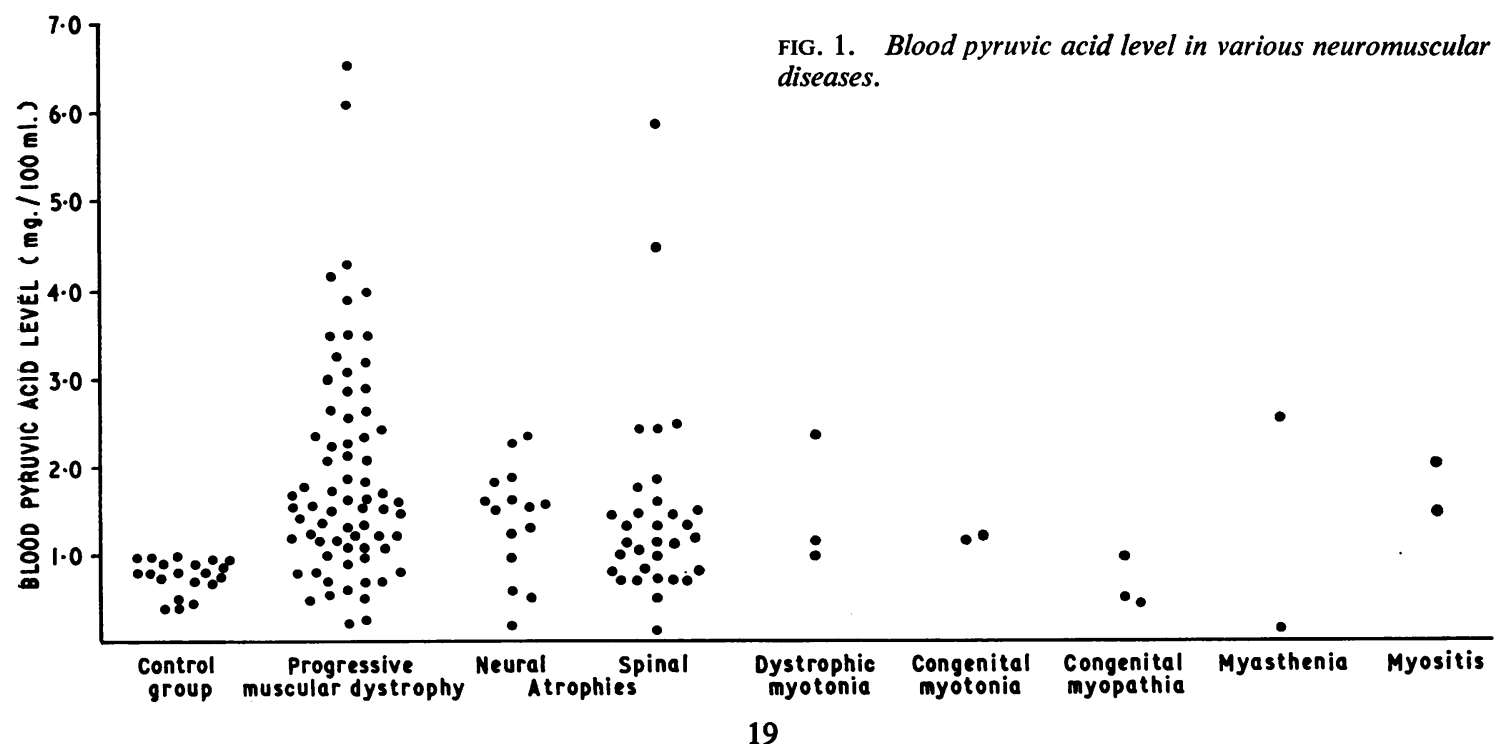

removing interfering substances by the method of Beutler and Yeh (1959). $\alpha$-Ketoglutaric acid was determined by the method of Keil and Sormova (1959). Oxalacetic acid was determined by the method of Friedemann and Haugen (1943) atter converting into pyruvic acid by means of citrate aniline. Blood glucose was determined by the method of Hagedorn and Jensen (1923). Serum glutamic-oxalacetic and glutamic-pyruvic transaminase activity was determined by the method of Reitman and Frankel (1957). Creatine and creatinine were determined in the blood by the method of Brod and Sirota (1948) and in urine by the method of Bonsnes and Taussky (1945). Biopsy specimens of muscle were obtained under local anaesthesia ( $0.5 \%$ novocaine) and prepared for determination of the content of the pyruvic and citric acid by the method of Taussky, Washington, Zubillaga, and Milhorat (1962). Non-collagen nitrogen in the muscular homogenates was determined by the method of Parnas and Wagner (1921).

A group of 130 patients with muscular disorders characterized by muscular atrophy was studied; it included 70 patients with progressive muscular dystrophy. The normal values for the individual substances were determined in $\mathbf{2 0}$ healthy persons.

FIG. 1. Blood pyruvic acid level in various neuromuscular diseases. 
RESULTS

An increase in the blood pyruvic acid content in progressive muscular dystrophy was confirmed. The increase, although not always observed (Fig. 1), was statistically significant at a significance level of $1 \%$ using Student's $t$ test. The blood pyruvic acid level was also elevated in most of muscular disorders of other kinds, showing values varying from normal to markedly raised.

No change was found in the level of lactic acid, $\alpha$-ketoglutaric acid, or oxalacetic acid (Table I) in any of the group of muscular disorders studied. The most interesting results obtained were those for citric acid level in the blood (Fig. 2). This was lowered in progressive muscular dystrophy in contrast to the values in other types of muscular disorders. The difference is statistically significant at a significance level of $1 \%$. In Fig. 2 the level of citric acid below $1.5 \mathrm{mg}$. per $100 \mathrm{ml}$. in certain cases first diagnosed as congenital myopathy or spinal atrophy is related to cases which later also appeared to be of muscular dystrophy. In none of the groups of muscular disorders studied was there any change in the blood concentration of glucose.

Attempts at correlating the degree of change

TABLE I

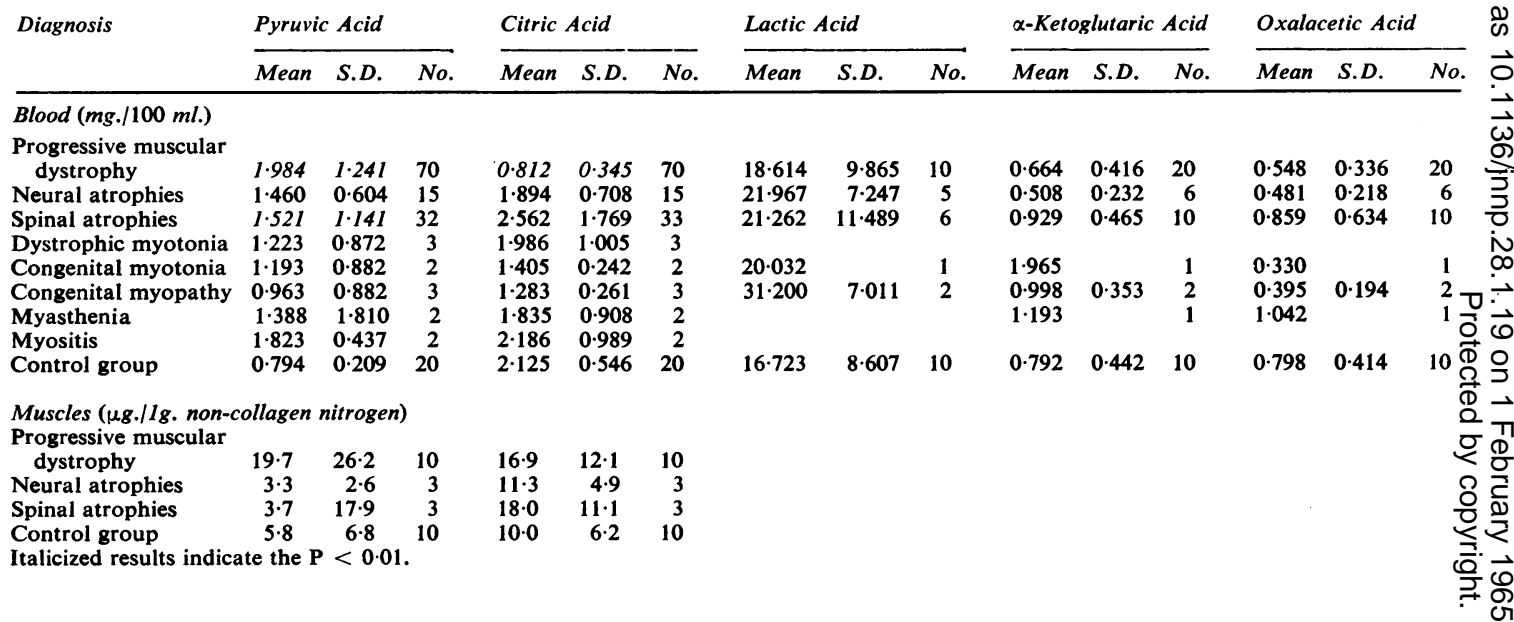

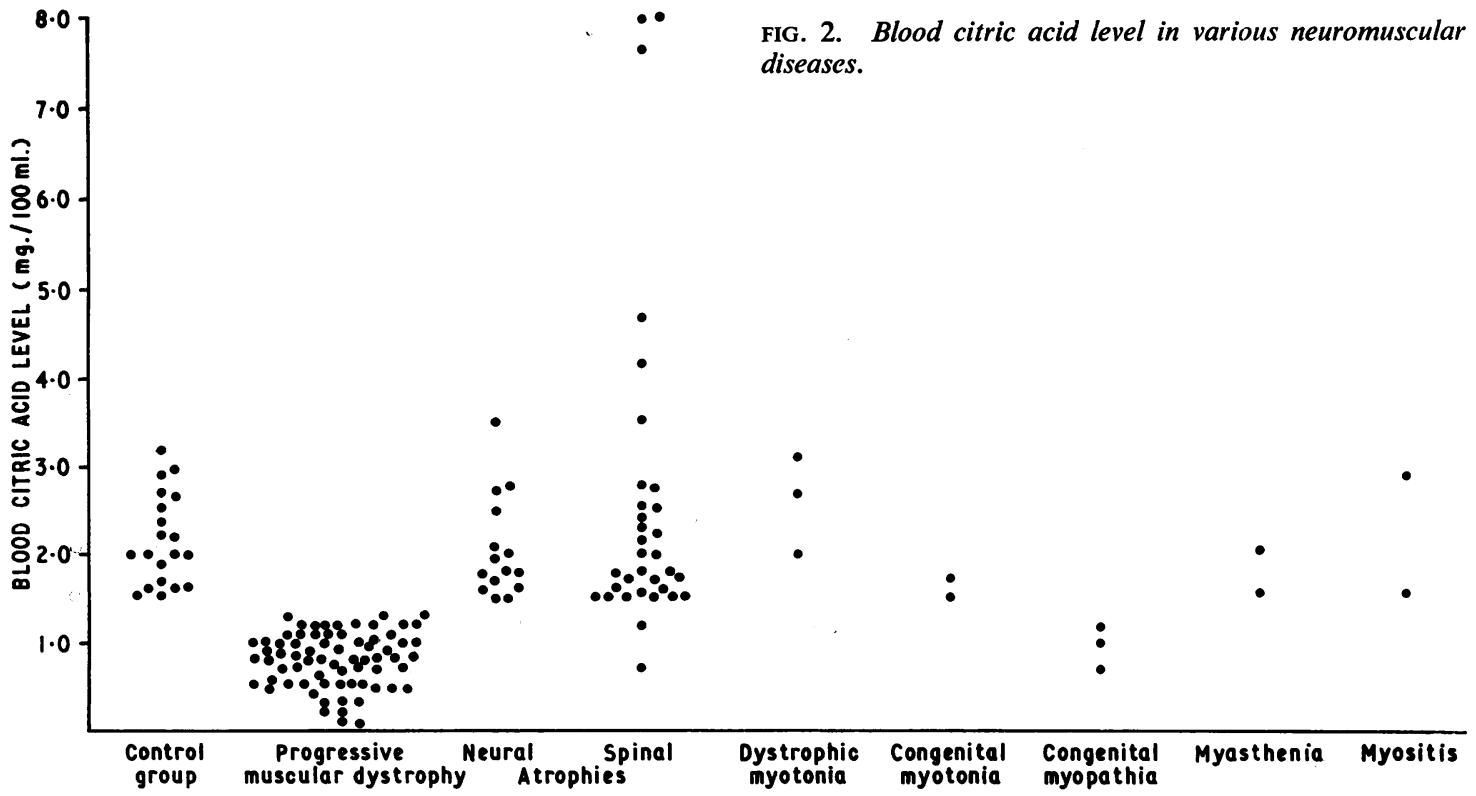
diseases. 


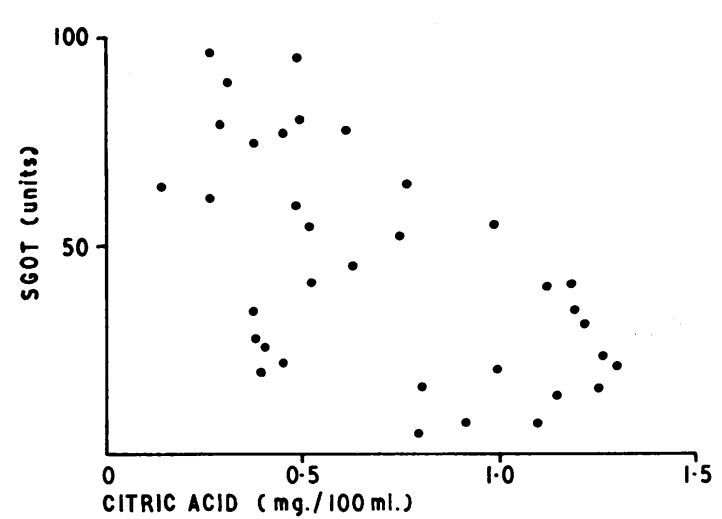

FIG. 3. Relation between glutamic-oxalacetic transaminase activity and citric acid level in the blood in progressive muscular dystrophy.

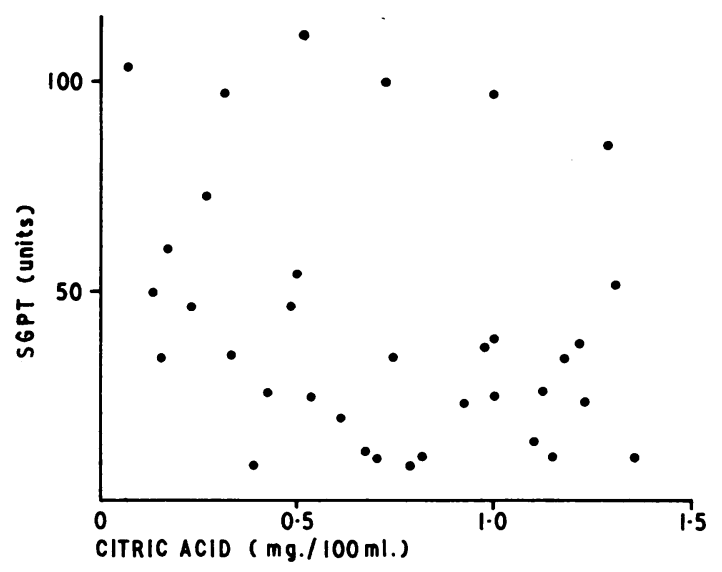

FIG. 4. Relation between glutamic-pyruvic transaminase activity and citric acid level in the blood in progressive muscular dystrophy.

observed in progressive muscular dystrophy with the severity of disturbances in the metabolism of creatine and creatinine and with sex did not reveal any characteristic phenomena.

Some tendency to increased transaminase activity was observed (Figs. 3 and 4) parallel to a decrease in the citric acid level in the blood. However, it is difficult to speak of a reciprocal correlation (correlation coefficient for SGOT $=+0.004$, for SGPT $=$ $+0 \cdot 15)$.

Determinations of pyruvic acid and citric acid content were performed in the muscle of 10 patients with progressive muscular dystrophy and of six patients with neurogenic muscular wasting. The control group consisted of 10 normal persons. In general, there were no differences in muscular con- tent of citric acid or pyruvic acid. However, in three of the 10 patients studied an increase in the pyruvic and citric acid levels greater than twice the standard deviation was found. Non-collagen nitrogen was chosen às a basis for calculation.

\section{DISCUSSION}

An increased blood pyruvic acid level in progressive muscular dystrophy was for the first time observed by Luzzato and Lodigiani in 1954. It was thought to be caused by a metabolic defect, and in a later study (Luzzatto and Ramelli, 1959) it was defined as the absence of phosphorylation enzymes. Also Beckmann and Billich (1962) have found an increased blood pyruvic acid content which was ascribed to a liver cell lesion caused by non-specific metabolic disturbances or products of nitrogen metabolism. Similar results have been obtained by Pansini and Sozio (1953). On the other hand, the presence of hyperpyruvicaemia in progressive muscular dystrophy has not been confirmed by the control studies of Cumings (1953), which, as well as those of other authors (Minazzi, 1958), indicate that this change is not specific for progressive muscular dystrophy. Results of the present studies confirm the increased pyruvic acid content in the blood in progressive muscular dystrophy and also the non-specific character of this change for that group of muscular diseases. The first results of these studies were published in 1961 (Niebrój-Dobosz, 1961).

During a study of the further steps in pyruvic acid metabolism a fall in the blood citric acid level was found. It should be stressed, however, that no change in the blood citric acid level similar to those observed in progressive muscular dystrophy was found in other muscular disorders. Raised blood pyruvic acid levels may be due either to the excessive production, resulting from increased oxidation of, in the first place, the carbohydrates, or to the blocking of the process by which pyruvic acid is transferred into the citric cycle pathway. The results obtained in progressive muscular dystrophy, hyperpyruvicaemia with a definite fall in blood citric acid level, might be due to the blocking of the process by means of which pyruvic acid is transferred into the Krebs cycle pathway, or to the inability of the organism to compensate for the probable scarcity of some citric cycle metabolites caused by their utilization in other metabolic processes. The latter possibility is improbable. A compensating influence is that of the transaminases, the activity of which is raised in a large percentage of patients with progressive muscular dystrophy. Also the elevation of malic acid dehydrogenase activity in these cases indicates compensation of some stages of the citric cycle 
(Coletta, Berni Canani, Rea, Schettini, and Cigala, 1962; Schettini, Rea, and Canani, 1961). The normal $a$-ketoglutaric and oxalacetic acid levels likewise provide evidence in favour of compensation for citric acid and further links of the citric cycle. It seems probable that oxidative decarboxylation is impaired. Simple and oxidative carboxylations, the remaining routes of introducing pyruvic acid into the citric cycle, may, however, be insufficient for oxidation of the excess of pyruvic acid, which is not only derived from carbohydrate metabolism. In muscular disorders of different types changes in the blood pyruvic acid content seem to be due only to an increased oxidation of carbohydrates or possibly of proteins.

The blood pyruvic acid content does not provide a full picture of the situation at the site of the muscle. For this reason, it was considered of interest to compare pyruvic and citric acid levels in blood with those in muscle. In accordance with the results of Lilienthal, Zierler, Folk, and Riley (1950), the reference base selected was non-collagen nitrogen. Pyruvic acid level in the muscle of dystrophics was normal but it should be kept in mind that a fall in the activity of glycogenolytic enzymes in muscle is not, as is known from the studies of Ronzoni, Berg, and Landau (1960), a factor limiting carbohydrate metabolism. Thus, decreased activity of glycogenolytic enzymes would not play the role of an agent limiting production of pyruvic acid. The normal citric acid level in the muscle in progressive muscular dystrophy confirms the normal function of the enzymes regulating the system of final combustion processes. Thus, inhibition of the oxidation processes does not take place in muscle.

An analysis of the group of subjects with progressive muscular dystrophy with reference to the patient's age, the type of dystrophy, duration of the disease, and severity of the course will be the subject of a separate report.

\section{SUMMARY}

In 130 cases of different kinds of muscular disease pyruvic and citric acid levels in the blood were determined; in 50 patients of this group the blood levels of lactic, $a$-ketoglutaric, and oxalacetic acids were determined. In cases of progressive muscular dystrophy there was a statistically significant fall in the blood citric acid content, with a concomitant hyperpyruvicaemia. In other types of neuromuscular disorder only the blood pyruvic acid level was increased. There were no characteristic changes found in other tricarboxylic acids or lactic acid in any of the groups of muscular diseases. In progressive muscular dystrophy there were no changes in pyruvic acid and citric acid levels in muscle as compared with other muscular diseases and with normal values. A possible mechanism of these changes is discussed.

This study is part of a research project supported by the N.I.H., Bethesda, U.S.A., under agreement no. 227702.

\section{REFERENCES}

Beutler, E., and Yeh, M. K. Y. (1959). A simplified method for the determination of citric acid. J. Lab. clin. Med., 54, 125-131.

Beckmann, R., and Billich, C. (1962). Die Leber bei der Dystrophia musculorum progressiva ERB. Med. Welt, pp. 1085-1094.

Bonsnes, R. W., and Taussky, H. H. (1945). On the colorimetric determination of creatinine by the Jaffe reaction. J. biol. Chem., 158, 581-591.

Brod, J., and Sirota, J. H. (1948). The renal clearance of endogenous 'creatinine' in man. J. clin. Invest., 27, 645-654.

Coletta, A., Berni Canani, M., Rea, F., Schettini, F., and Cigala, F. (1962). Aspetti biochimici della distrofia muscolare progressiva. Indagini sul quadro enzimo-plasmatico a sul comportamento di alcuni enzimi muscolari in rapporto al quadro istologico. Pediatria (Napoli), 70, 779-811.

Cumings, J. N. (1953). Creatine and guanidoacetic acid metabolism in muscle diseases. Brain, 76, 299-310.

Friedemann, T. E., and Haugen, G. E. (1943). Pyruvic acid; II. The determination of keto acids in blood and urine. J. biol. Chem., $147,415-442$.

Greig, M. E. (1947). A micromethod for the determination of 1-(+) lactic acid. Science, 105, 665-666.

Hagedorn, H. C., and Jensen, B. N. (1923). Zur Mikrobestimmung des Blutzuckers mittels Ferricyanid. Biochem. Z., 135, 46-58.

—, - (1923). Die Ferricyanidmethode zur Blutzuckerbestimmung. II. Ibid., 137, 92-95.

Keil, B., and Sormova, Z. (1959). In Laboratorni technika biochemie, p. 560. NCAV, Praha.

Lilienthal, J. L., Zierler, K. L., Folk, B. P., and Riley, M. J. (1950). A reference base and system for analysis of muscle constituents. J. biol. Chem., 182, 501-508.

Luzzatto, A., and Lodigiani, E. (1954). Reperto di iperpiruvicemia nella distrofia muscolare progressiva. Minerva med. (Parte Sci.), 45. $725-729$.

-, and Ramelli, E. (1959). L'iperpiruvicemia nella distrofia muscolare progressiva è una caratteristica genica? Cervello, 35, 377-392.

Minazzi, M. (1958). Contributo allo studio della dermatomiosite. Nevrone, 62, 183-200.

Pansini, R., and Sozio, N. (1953). Ricerche sulla fisiopatologia muscolare dell'uomo; comportamento dell'alcoolemia, piruvicemia e glicemia nel circolo venoso superficiale dopo carico d'insulina in miopatici. Rass. Fisiopat. clin. ter., 25, 421-429.

Parnas, J. K., and Wagner, R. (1921). Uber die Ausfuhrung von Bestimmungen kleiner Stickstoffmengen nach Kjeldahl. Biochem. Z., 125, 253-256.

Reitman, S., and Frankel, S. (1957). A colorimetric method for the determination of serum glutamic oxalacetic and glutamic pyruvic transaminases. Amer. J. clin. Path., 28, 56-63.

Ronzoni, E., Berg, L., and Landau, W. (1960). Enzyme studies in progressive muscular dystrophy. In Neuromuscular Disorders. Res. Publ. Ass. Res. nerv. ment. Dis., 38, pp. 721-729.

Schettini, F., Rea, F., and Berni Canani, M. (1961). Sul comportamento dell'attivita'malicodeidrogenasica serica in bambin affetti da distrofia muscolare progressiva. Boll. Soc. Ital. Biol. sper., 37, 1206-1208.

Taussky, H. H., Washington, A., Zubillaga, E., and Milhorat, A. T. (1962). Citric acid in tissues of normal and dystrophic animals. Nature (Lond.), 196, 1100-1101. 